Ralph F. Wilson

is the author/editor of Wilsonweb. com, which Business Week called: 'bar none the best e-commerce resource out there', as well as numerous books on a variety of web marketing topics. He holds the DMin degree from Fuller Theological Seminary.

James B. Pettijohn is the author of numerous academic journal papers dealing with web marketing and the use of the internet in management education. He holds a PhD degree in business administration from the University of NebraskaLincoln. He is Professor of Finance and e-Business, Missouri State University.
Keywords: search engine, rankings, optimisation
Dr James Pettijohn Missouri State University 901 S. National Springfield, MO 65804, USA Tel: +1 (417) 8366174 E-mail: JamesPettijohn@missouristate.edu

\section{Search engine optimisation: A primer on linkage strategies}

\author{
Ralph F. Wilson and James B. Pettijohn \\ Received: 22 May 2005
}

\begin{abstract}
This paper and its previously published companion discuss the fundamentals of how search engines operate and present a number of suggestions that e-marketers can follow to improve their sites' search engine rankings. Since those rankings basically are determined by two overall factors, keywords and links from other sites, our first paper dealt with strategies for optimising a site's keywords in preparation for search engine spiders, while the present paper deals with strategies for obtaining linkages from other sites. Although the primary focus is on a site's ranking in Google searches, the information provided should prove useful for increasing a site's ranking on other search engines as well. This information is suitable for e-marketers, as well as for academicians interested in learning the fundamentals of search engine optimisation.

Journal of Direct, Data and Digital Marketing Practice (2007) 8, 210-225. doi:10.1057/palgrave.dddmp.4350052
\end{abstract}

\section{Introduction}

Paid advertising through pay per click (PPC) advertisements on search engines is quite an effective method of driving traffic to a website, but it can be costly. Because of the cost factor, a very important companion to PPC advertisements can be taking steps to obtain a high rank within a search engine's 'natural' or 'organic' search results; that is, within the engine's regular, unpaid, results. Achieving a high ranking can save an e-business thousands, perhaps even tens of thousands, of dollars in advertising and can produce synergistic results when combined with a PPC ad campaign.

The proper use of keywords and strategic acquisition of incoming links to a website can result in higher 'natural' or 'organic' rankings for webpages, an important component of what is called 'search engine optimisation' (SEO). In part one of this two-part series on SEO, we pointed out that, since search engine optimisation remains an important component of e-marketing, it is important for the online marketer to grasp the basics of SEO. That requires an understanding of the fundamentals of how search engine rankings work. We believe that developing an introductory SEO knowledge requires an understanding of the following:

- What is search engine ranking all about?

- How does a website get higher rankings? 


\section{Providing simplified answers}

\section{Spamming}

\section{Google's innovation}

- Does one have to pay someone to increase their search engine ranking?

One objective of this two-part series is to provide quite simplified answers to the first two questions listed above so that the e-marketer can better understand the fundamentals of search engine rankings and how online businesses can improve their rankings through the strategic acquisition of incoming links. The answer to the third question depends upon both the time constraints facing the e-marketer and how effectively he/she acts using the knowledge gained from our answers to the first two questions. Since Google's 39 per cent market share makes it the dominant search engine, most of the discussion in this, as well as our previous, paper is directed toward Google's approach to ranking. ${ }^{1}$

\section{Ranking is based on two factors}

For those who have not read part one of this series, it is important to point out that, during the formative years of the commercial internet, search engines were easy to deceive. All the owner of a website had to do was repeat a keyword dozens of times on its webpage, and the page would rapidly rise to the top of the rankings. Today, however, such a practice is considered spamming and can result in a website being banned from a search engine's index. While keywords are still important in SEO, several years ago Google introduced another set of factors that affect ranking: the quantity, quality and context of incoming links to a website. The result of Google's innovation is that the pattern of linkage to a particular domain has a great deal to do with how high a site is ranked with respect to these incoming link factors for a particular keyword. Thus, today, the search engine ranking of any given webpage is based on two factors:

1. The keywords on that webpage, which was the focus of the first paper in this series. The more focused and clear the content is on the webpage, the greater are the chance of ranking high for the main keywords on that webpage.

2. The quantity, quality and context of incoming links to a domain name, which is the focus of this paper.

Yet another point made in first installment in this two-part series is that Google employs a complex algorithm based on the above two factors to determine which sites are on top for any keyword search. The Google website explains the process this way:

- 'PageRank (ie, the software behind Google's ranking technology) performs an objective measurement of the importance of web pages by solving an equation of more than 500 million variables and 2 billion terms. Instead of counting direct links, PageRank interprets a link from Page A to Page B as a vote for Page B by Page A. PageRank then assesses a page's importance by the number of votes it receives. PageRank also considers the importance of each 


\section{How strategic acquisition of incoming links contributes to search engines' rankings}

page that casts a vote, as votes from some pages are considered to have greater value, thus giving the linked page greater value.

Important pages receive a higher PageRank and appear at the top of the search results. Google's technology uses the collective intelligence of the web to determine a page's importance. There is no human involvement or manipulation of results ...'.

- 'Google's search engine also analyses page content (through a process Google calls "Hypertext Matching Analysis"). However, instead of simply scanning for page-based text (which can be manipulated by site publishers through meta-tags), Google's technology analyses the full content of a page and factors in fonts, subdivisions and the precise location of each word. Google also analyses the content of neighbouring web pages to ensure the results returned are the most relevant to a user's query'. ${ }^{2}$

Since the explanations of the two factors that affect page rankings (keywords and linkages) are each rather lengthy, we chose to deal with each factor in a separate paper. As we previously mentioned, this paper provides a basic explanation of how strategic acquisition of incoming links contributes to search engines' rankings. It also discusses a number of strategies for obtaining quality links. The information we provide draws heavily from the experience of one of the authors as an e-commerce consultant, publisher and author of a recent book dealing with SEO. It also capitalises on his practical experiences as a merchant managing a commercial website. This paper should prove useful to e-marketers who want to gain a better understanding of search engine rankings, as well as to instructors who teach and study a variety of e-business-related topics. Following an introductory discussion dealing with Google PageRank, we discuss how linkage patterns affect a site's ranking for any particular keyword. We conclude by offering 12 linking strategies that have the potential to increase incoming links to a website, thus increasing that site's search engine rankings.

\section{How Google PageRank works}

It is difficult to provide a definitive answer to the question of how Google PageRank works, since there is a significant amount of disagreement regarding how Google uses links to determine PageRank. For the general discussion of Google's presumed approach, we reviewed the work of Mike Grehan, author of Search Engine Marketing: The essential best practice guide, who interviewed executives at Google and other search engines to understand their approaches. $^{3}$

Since webpage analysis by itself is notoriously subject to manipulation and fraud, Google introduced the concept of linking as a way to determine the relevance of a page. Essentially, Google's creators developed a linkage map of the internet that forms Google's superstructure. Google continues to evolve, but there is general 
agreement that the factors in its unbelievably large linkage map include, but certainly are not limited to, the following:

- Industry hubs: For each discipline or topic, Google determines which are the dominant authorities and information hubs. Usually, these are the sites with the most links to them. Then Google looks at sites to which the information hubs are linking. Sites that merit a link from an industry leader are considered more important than sites without such recognition. Thus, in Google's system, sites with links from industry leaders should rank higher in its search listings than sites without such links.

- Number of incoming links: Google has the ability to count the absolute number of incoming links to a website. It also can subtract from that total any cross-linking from websites within that domain

\section{Three factors} or hosted from the same IP address. All other things being the same, the more incoming links a site has, the higher that site ranks. Interestingly enough, even if these links are from small websites, getting a high number of incoming links appears to help increase a site's ranking.

- Link context: Google also determines the context of each link - by the industry or topic of the site, the relative importance of the website itself, the keywords on the webpage containing the link and any keywords contained in the hyperlink itself. This practice explains why links from uncategorised 'link farms' are quite obvious and are discounted by Google (A link farm is 'a network of websites which are densley connected with each other') ${ }^{4}$

Google takes PageRank, along with other linking information, and provides weighting to each linking factor according to its own secret, proprietary algorithm. This information and the indexing information obtained from Googlebot for a particular webpage are combined to determine that page's ranking for any relevant keyword. For example, assume that a webpage about 'silver bullets' from two different websites has been indexed and (to simplify this explanation) both are clearly focused on 'silver bullets' to the exact same degree. The webpage with the higher Google PageRank (based on the pattern of linkage) would rank higher than the webpage with the lower PageRank. Furthermore, if we assume that both the indexing and PageRank are exactly the same, then the relevance of the links, determined by the hyperlinked text and appropriate synonyms on pages that link to the page in question, would come into play.

\section{Determining a website's PageRank}

It is possible to determine a site's relative importance, and hence its PageRank, in two ways:

- Google Toolbar (toolbar.google.com), which installs in a web browser, can be configured to display Google's PageRank (on a 1-10 scale) for each page it indexes. A link from a site with 

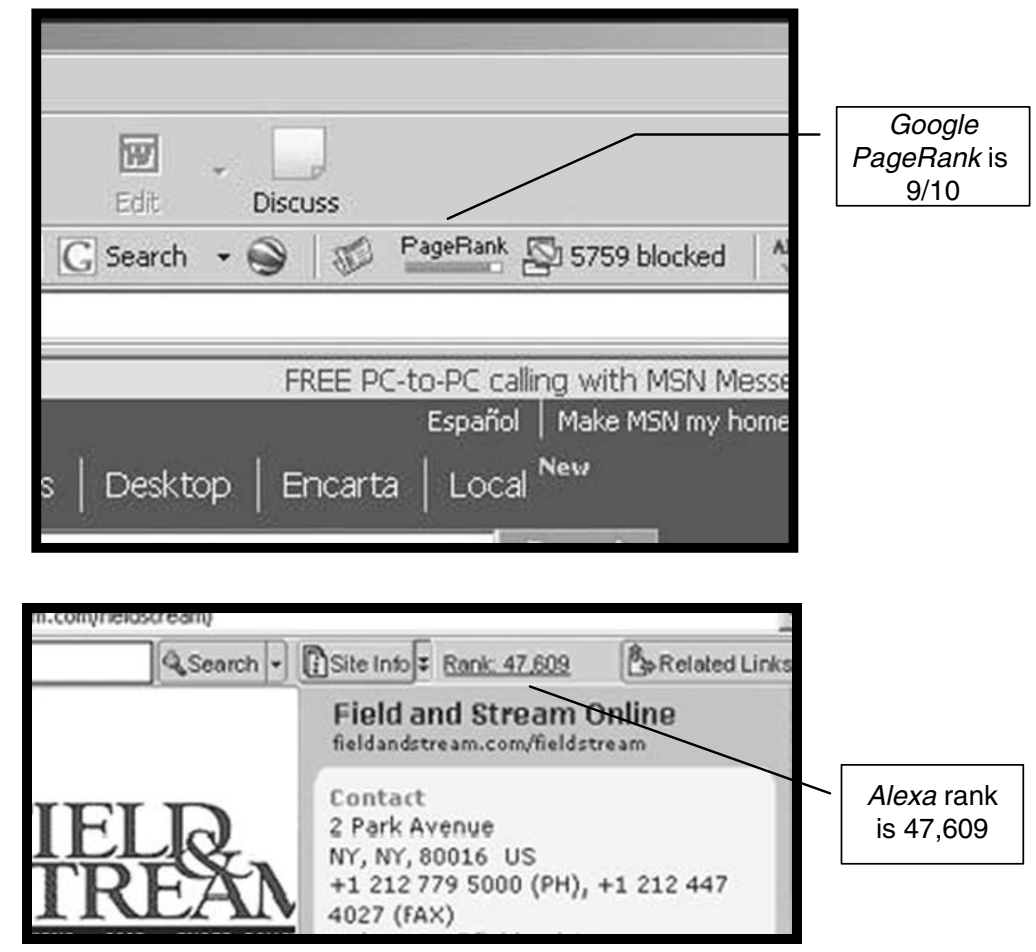

Figure 1: Examples of Google PageRank and Alexa Toolbar Rank

a PageRank of 10 is significantly more valuable than a link from a small, new site with a PageRank of 1 . Figure 1 contains a partial image of MSN's homepage showing Google's PageRank approximately in its centre. When one 'mouses over' the gauge, an information note appears telling the user that, in this case, the PageRank is 9 out of 10 . However, many believe that the PageRank shown by Google may not be fully accurate, since Google is not showing reporting all links to the site in question. $^{5}$

- Alexa Toolbar (www.alexa.com) also installs in a web browser. It shows Alexa's 'average traffic rank', based on sites visited by Alexa Toolbar users. The most popular site is ranked number 1, the next most popular number 2 , and so on into the hundreds of thousands. Figure 1 also included a cropped image showing a site's Alexa Toolbar rank.

\section{Analysing the linking pattern to a website and to competing sites}

It is reasonably simple to discover how many sites link to a particular website, as well as to competing sites. The most expedient way is to ask Google by entering the following syntax in a Google search: 


\section{Software available to e-marketers}

For example, if the URL of a merchant's website is www. ABCAmmunition.com, entering

'link: www.ABCAmmunition.com'

as a Google search will result in a listing of all websites that contain links to www.ABCAmmunition.com.

While the number of incoming links can be easily determined, from a practical standpoint the amount of time to analyse the data obtained in this manner can be quite daunting. Fortunately for the e-marketer, a whole class of software is now available that does an excellent job of analysing links. One of the first tools available for use with Windows was OptiLink Link Reputation Analyzer. ${ }^{6}$ OptiLink queries Google and other search engines to find links to your website (or to competitors' sites) and provides a great deal of information about the linking patterns, including the following:

- what keywords are on the selected target page

- what keywords are contained in links to the target page

- what keywords are contained in the titles of pages that link to the target page

- what domains and IP addresses link to the target page

- how many incoming links there are to every webpage that links to the target page, and how many outgoing links are there from every webpage that links to the target page.

Sorting on 'incoming links' will reveal 'authorities' for the target page's industry or field, while sorting on the 'outgoing links' will produce a listing of the 'hubs' for that same industry or field. ${ }^{6}$ It is our experience that tools such as OptiLink help a site owner clarify and refine his/her own linking strategy by facilitating the following activities:

- checking interlinking between the owner's sites

- adding and modifying keywords on the owner's webpages to make the best use of existing incoming links

- finding undesirable links and seeking to have them removed or changed

- identifying hubs and authorities in the owner's subject area so he/she can ask for appropriate links

- narrowing the focus of each of the owner's webpages to get more effective linking

- analysing the links and strategies that the owner's competitors are using.

As an example of how this process can be of benefit, when one of the authors used OptiLink to analyse links to his commercial, contentoriented website, the results led to a quite significant change in the linking strategy for that site. What he discovered was that most sites were linking either to the author's company name or to his personal 


\section{2 linking strategies}

name (we will call it 'Smith'). This was rather perplexing, since his business does not depend on his website scoring high for the keyword 'smith.' Instead, his site depends on linkages from keywords or phrases such as 'internet marketing', 'web marketing' and 'e-commerce', and the link analysis showed significantly fewer links based on the latter keywords and phrases. Once this linking pattern was discovered, the author began making an overt attempt to specify the exact wording in links to his site in the free content he distributes to other websites. This wording, which is designed to produce links from the keywords and phrases that are important to his site, has been successful.

To summarise, if the e-marketer learns that his/her website ranks lower than competing sites, linking software can be used to analyse which important (ie, high PageRank) sites link to those competing sites rather than to his/her site. Given this information, the next logical step is to seek links from those sites with high PageRanks. A nonexhaustive listing of link popularity tools, other than OptiLink, is provided in Table 1.

\section{Linking strategies}

The following paragraphs briefly discuss 12 linking strategies that can help increase a site's link popularity and help it obtain the type of high-quality links that increase PageRank. We recommend the adoption of a number of these strategies for any SEO campaign.

1. Obtain Directory Listings: The first, and perhaps most obvious, linking strategy is making sure the site in question is listed in important directories. As can be seen in Table 2, some directories charge a fee, while others are free. We do not believe that it is important to seek listings from directories with low Google PageRanks. Furthermore, we see no reason to accept offers to upgrade a free listing to a more prominent paid listing on a directory. While it is possible that such an upgrade might increase a site's traffic, the upgrade will have no effect on PageRank.

Software such as SubmitWolf 7.0, part of the Trellian SEO ToolSet 2.0 (see Table 1), compiles facts about a website (ie, keywords, site category, webmaster contact information, etc) and will register that site with hundreds of search engines, directories and link pages. To keep its list of sites current, it adds new sites as they appear and purges old sites when they cease to exist.

SubmitWolf's capabilities notwithstanding, we see little benefit from submitting to unknown search engines, since the search market is dominated by the well-known ones, such as Google, Yahoo! and MSN. Furthermore, we caution against submitting to automated link pages (webpages containing links to other sites). The reason for this is that there is a high potential that at least some of these pages could be link farms, and the reader will recall from earlier in the paper that Google discounts link farm listings. In addition, the merchant will want to avoid free-for-all (FFA) sites because of their propensity to spam merchants naïve enough to list their sites on them. If, however, SubmitWolf can submit a site quickly and easily to specialty directories, 
Table 1: Selected link popularity software

\begin{tabular}{|c|c|c|}
\hline Name of Website & URL & Comments \\
\hline Linkpopularity.com & www.linkpopularity.com & $\begin{array}{l}\text { Lets the user enter a URL and } \\
\text { simultaneously query Google, Yahoo } \\
\text { and MSN. Results are shown in terms } \\
\text { of the number of links each search } \\
\text { engine shows to the URL that was } \\
\text { entered. }\end{array}$ \\
\hline $\begin{array}{l}\text { MarketLeap's Link } \\
\text { Popularity Tool }\end{array}$ & $\begin{array}{l}\text { http://www.marketleap. } \\
\text { com/publinkpop }\end{array}$ & $\begin{array}{l}\text { Lets the user enter a URL and } \\
\text { simultaneously query Google/AOL, } \\
\text { Yahoo/FAST/Altavista, MSN and } \\
\text { HotBot. Results are shown in terms } \\
\text { of the number of links each search } \\
\text { engine shows to the URL that } \\
\text { was entered. Shows an 'industry } \\
\text { benchmark' report with sites ranked } \\
\text { as limited presence, average presence, } \\
\text { above average presence, contender, } \\
\text { player and 900-pound gorilla. }\end{array}$ \\
\hline $\begin{array}{l}\text { Bruce Clay's } \\
\text { SEOToolSet }\end{array}$ & $\begin{array}{l}\text { http://www.bruceclay. } \\
\text { com/web_rank.htm }\end{array}$ & $\begin{array}{l}\text { Includes more specific tools for SEO } \\
\text { than other software we have seen. } \\
\text { The Link Analysis tool searches three } \\
\text { search engines for links to a site } \\
\text { through keywords the user provides. } \\
\text { A Summary report identifies major } \\
\text { competitors for those keywords. The } \\
\text { user then can run a Link Analysis } \\
\text { comparing links to the five top } \\
\text { competing sites with links to the } \\
\text { site in question. The analysis shows } \\
\text { which sites link to each competitor, } \\
\text { ranked in descending order by Google } \\
\text { PageRank. The best sites from whom } \\
\text { to request a link are presented in an } \\
\text { easy-to-access format and can be } \\
\text { saved as an Excel spreadsheet. }\end{array}$ \\
\hline $\begin{array}{c}\text { Caphyon Advanced } \\
\text { Link Manager } 2.0\end{array}$ & $\begin{array}{l}\text { http://www. } \\
\text { advancedlinkmanager. } \\
\text { com/ }\end{array}$ & $\begin{array}{l}\text { Platform-independent Java software, } \\
\text { which does an excellent job of } \\
\text { compiling a list of links to your site } \\
\text { from dozens of search engines, will } \\
\text { spider these links in the future to } \\
\text { make sure they still exist, as well as } \\
\text { to detect any new links to the desired } \\
\text { site. A good option for tracking a site's } \\
\text { collection of linking sites as well as } \\
\text { for discovering the linking patterns of } \\
\text { competing sites. }\end{array}$ \\
\hline $\begin{array}{l}\text { Trellian SEO Toolkit } \\
\text { v.2.0 }\end{array}$ & http://www.trellian.com & $\begin{array}{l}\text { Includes a Link Popularity tool. Checks } \\
\text { rankings on 'all major search engines } \\
\text { (user selects which ones);' tracks } \\
\text { ranking history over time; user can } \\
\text { select from several report formats. } \\
\text { Lacks a number of features present in } \\
\text { other programs }\end{array}$ \\
\hline
\end{tabular}

this capability can be of considerable value. Fortunately, the merchant can tell SubmitWolf not to submit to FFA sites and link farms. Finally, SubmitWolf informs the user of the volume of e-mail sent by various sites, so one can avoid submitting to sites that spam after submission. 
Table 2: Leading online directories

\begin{tabular}{|c|c|c|}
\hline Directory & URL & Comments \\
\hline Yahoo! Directory & dir.yahoo.com & $\begin{array}{l}\text { Yahoo! Express Submit costs } \$ 299 \\
\text { annually. Uses human editors; has many } \\
\text { incoming links; has a PageRank of } 9 \\
\text { on the Directory homepage itself. An } \\
\text { important listing to have, if it can be } \\
\text { afforded. }\end{array}$ \\
\hline Open Directory Project & www.dmoz.com & $\begin{array}{l}\text { Largest human-edited directory on the } \\
\text { internet. Short of volunteer editors, so } \\
\text { listing may take a while. Is a free and } \\
\text { important site. The DMOZ homepage } \\
\text { has a page rank of } 8 \text {, and this directory } \\
\text { feeds information to all the major search } \\
\text { engines. If one gets impatient and } \\
\text { resubmits, his/her site loses its place in } \\
\text { the queue. }\end{array}$ \\
\hline Froogle & www.froogle.com & $\begin{array}{l}\text { Google's product search tool. Can link } \\
\text { a site's product pages free and update } \\
\text { them with a data upload approximately } \\
\text { every month, thus help the pages to } \\
\text { be shown in appropriate spots in both } \\
\text { Google and Froogle searches. }\end{array}$ \\
\hline About.com & www.about.com & $\begin{array}{l}\text { Provides annotated links to some high- } \\
\text { quality resources. PageRank of } 9 / 10 \text { on } \\
\text { homepage. }\end{array}$ \\
\hline Business.com & www.business.com & $\begin{array}{l}\text { Provides annotated links to business sites. } \\
\text { PageRank of } 7 / 10 \text { on homepage. }\end{array}$ \\
\hline $\begin{array}{l}\text { Trade Association } \\
\text { Directories }\end{array}$ & Various & $\begin{array}{l}\text { The e-merchant may be entitled to a free } \\
\text { directory listing on a website related } \\
\text { with its business. If payment is required, } \\
\text { however, it might produce an attractive } \\
\text { ROI, since that trade association is likely } \\
\text { to be a hub or authority in Google's } \\
\text { linking map }\end{array}$ \\
\hline
\end{tabular}

\section{Strategies for reciprocal linking}

2. Reciprocal Linking: Locating complementary sites, linking to them and asking for a link in return is known as 'reciprocal linking' and merits an extended discussion. Although sites willing to enter into a reciprocal linking agreement may have a low level of traffic, linking between complementary and/or similar sites provides search engines with contextual links that can help a site rank higher in the fields it deems to be important. We recommend the following reciprocal linking strategies:

- Create special link pages on which to list links to other sites, making certain that your site's main page clearly links to those link pages. Develop a logical grouping for the links to your reciprocal linking partners. For example, ABC Ammunition might group the ammunition links together on one page and target shooting links on another. And remember, if you cannot recommend a site to your site's own visitors, a link to it should not appear on your site. 
- Potential reciprocal linking partners can be identified using tools such as Arelis Reciprocal Links Solution (www.axandra-linkpopularity-tool.com) and Zeus Link Reciprocal Link Generator (www.cyber-robotics.com/), which spider the web looking for websites that contain keywords specified by the user. Both these tools also maintain a site's link pages and monitor links to and from linking partners. We do caution the reader, however, not to use the ability of these tools to automate the e-mail contact process, since automated messages most likely will be deleted without action. Instead, we recommend that the merchant take the time to make personal contacts by e-mail or telephone.

- When contacting a potential reciprocal linking partner, make certain that the value proposition is clearly stated; that is, how the reciprocal links will potentially benefit both the sites by slightly increasing the Google PageRanks, and ultimately the search engine rankings, of each. Provide the potential partner with a reason why his site should link to your site. Any savvy e-marketer will want to know how his/her site will benefit from this link as well as how visitors to his/her site might benefit from the link. Being prepared to provide a clear explanation of the process should increase the likelihood of obtaining the desired link.

- Once a potential partner agrees to a reciprocal linking arrangement, it is important to specify the exact text wanted in the hyperlink pointing back to your site. For example, instead of a link to 'ABC Ammunition' (which might help you rank higher for ammunition only), the e-marketer might request a link to 'Silver Bullet Manufacturers, ABC Ammunition' (which helps ABC rank higher for both 'silver bullet' and 'ammunition'). This is good practice because the reader will recall that Google takes note of both the context of the linking webpage and any keywords contained in the link to your site. This information, in turn, assists Google in determining which webpages are the most 'relevant' when someone initiates a keyword search.

- Finally, we recommend persistence; that is, when no response is forthcoming, try again. Locate the site owner's telephone number in an online directory such as Yahoo! Yellow Pages (yp.yahoo.com) or Whois (www.whois.com) and call him or her. Although obtaining reciprocal links can be time-consuming, be patient since the return grows as the number of incoming links increases and your site's PageRank increases.

Like most other SEO-related tasks, the process of obtaining incoming reciprocal links can be automated. Various programs can be installed on your website that allow visitors to select their own category for a link, allow them to submit a proposed link, notify your webmaster so that he/she can either accept or reject the proposed link and periodically spider existing links to your site to make sure the partners are still 'out there.' For the e-marketer who is conducting an extensive reciprocal linking campaign, automating the process can ease the burden of its 
Table 3: Representative reciprocal incoming link management tools

\begin{tabular}{|c|c|c|}
\hline Name of tool & URL & Comments \\
\hline $\begin{array}{l}\text { Duncan Carver's Link } \\
\text { Management Assistant }\end{array}$ & $\begin{array}{l}\text { www.onlinemarketingtoday. } \\
\text { com/software/link- } \\
\text { management }\end{array}$ & $\begin{array}{l}\text { Makes use of PHP and a MySQL } \\
\text { database. Reasonably powerful } \\
\text { and free at this writing. }\end{array}$ \\
\hline $\begin{array}{l}\text { Linking } 101 \text { Link } \\
\text { Management Script }\end{array}$ & $\begin{array}{l}\text { www.linking101.com/ } \\
\text { orders.htm }\end{array}$ & $\begin{array}{l}\text { Flat-file database of linking sites. } \\
\text { Written in Perl. Simple, Unix- } \\
\text { based program that can install } \\
\text { where webmaster has access } \\
\text { to the CGI-bin directory. Cost } \\
\text { is } \$ 55 .\end{array}$ \\
\hline LinksManager & $\begin{array}{l}\text { linksmanager.com/ } \\
\text { cgi-bin/neka/neka. } \\
\text { cgi?AID=26647 }\end{array}$ & $\begin{array}{l}\text { Automated linking service that } \\
\text { automatically FTPs updated } \\
\text { links pages to your website. } \\
\text { Cost is } \$ 19.95 / \text { month for up to } \\
50 \text { categories. Thirty-day trial } \\
\text { available. A good alternative } \\
\text { for those who cannot use a } \\
\text { CGl or PHP program. }\end{array}$ \\
\hline
\end{tabular}

\section{Proceed with caution}

administration; however, few, if any, of these programs employ a pass code that prevents the inquiry process from being automated from the other end. The lack of this capability, of course, increases the need to manually purge unwanted links. Table 3 provides a listing of representative incoming link management tools that can automate the reciprocal linking process on a website.

While there are various sites where e-marketers seeking linking partners can find each other, we feel the reader should approach these sites with caution, since many of their members will be quite indiscriminate. Recall that one of the methods search engines employ to classify your site is its incoming links. If these 'incomings' originate from known spammers or link farms, you can be sure GoogleBot will discover that fact. We also strongly advise against linking to sites that have no relationship to your site so that Google, as well as other leading search engines, will categorise your site and content in the proper context, thus allowing your site to rank higher for the keywords that make a difference. Table 4 includes a list of sites that can be used to locate linking partners.

Directories of link exchanges also can be of use, but the e-marketer should take care because many who list in such directories are indiscriminate about the sites to which they link. The most significant of these are:

- Google Directory for Link Popularity >Reciprocal Links, which lists more than 30 link exchange directories arranged in descending order according to their Google PageRank (http://directory.google. com/Top/Computers/Internet/Web_Design_and_Development/ Promotion/Link_Popularity/Reciprocal_Links/?il=1).

- Yahoo! Directory for Internet Promotion $>$ Banner and Link Exchanges. (http://dir.yahoo.com/Business_and_Economy/ 
Table 4: Sites designed to assist in locating potential reciprocal linking partners

\begin{tabular}{|c|c|c|}
\hline Site name & URL & Comments \\
\hline SiteSell Value Exchange & $\begin{array}{l}\text { http://value-exchange. } \\
\text { sitesell.com }\end{array}$ & $\begin{array}{l}\text { Allows you to register your site } \\
\text { and assists in locating interested } \\
\text { link exchange partners with sites } \\
\text { with similar keywords to yours. } \\
\text { Free. }\end{array}$ \\
\hline 123ExchangeLinks.com & $\begin{array}{l}\text { www.123exchangelinks. } \\
\text { com/ }\end{array}$ & $\begin{array}{l}\text { 'Provides website owners with a } \\
\text { tool to find quality link exchange } \\
\text { partners...' Potential links show } \\
\text { Alexa Traffic Ranks, contact } \\
\text { information, location of the site's } \\
\text { links page and a means to report } \\
\text { linking problems. }\end{array}$ \\
\hline LinkExchanged! & www.linkexchanged.com & $\begin{array}{l}\text { Free public link exchange } \\
\text { directory. Premium service } \\
\text { (\$9.95/month) provides } \\
\text { unlimited link exchanges with } \\
\text { premium and public members. }\end{array}$ \\
\hline LinkMarket & www.linkmarket.net & $\begin{array}{l}\text { Free, advertising-supported, link } \\
\text { exchange directory. }\end{array}$ \\
\hline $\begin{array}{l}\text { Most Relevant Links } \\
\text { Directory }\end{array}$ & $\begin{array}{l}\text { http://www.most-relevant- } \\
\text { links.com/ }\end{array}$ & $\begin{array}{l}\text { Free, advertising-supported, link } \\
\text { exchange directory. }\end{array}$ \\
\hline GoTop Link Exchange & www.gotop.com & $\begin{array}{l}\text { Charges a one-time fee of } \$ 29.95 \\
\text { to place your site at the top of } \\
\text { your category so you get more } \\
\text { link requests. }\end{array}$ \\
\hline Linkateer Link Exchange & $\begin{array}{l}\text { www.linkateer.com/link- } \\
\text { exchange.asp }\end{array}$ & Free link exchange directory. \\
\hline Linkexchangeit & www.linkexchangeit.com & $\begin{array}{l}\text { Free link exchange. Site also has } \\
\text { free SEO webmaster tools. }\end{array}$ \\
\hline LinkPartners.com & www.linkpartners.com & $\begin{array}{l}\text { Free link exchange directory } \\
\text { affiliated with LinksManager link } \\
\text { page management software. }\end{array}$ \\
\hline LinkAdage Exchange & $\begin{array}{l}\text { http://www.linkadage. } \\
\text { com/link_exchange.htm }\end{array}$ & $\begin{array}{l}\text { Offers a free automated link } \\
\text { exchange service as well as a } \\
\text { manually link exchange forum. } \\
\text { Attempts to prevent websites } \\
\text { with search engine penalties } \\
\text { from using the service. }\end{array}$ \\
\hline
\end{tabular}

\section{Business_to_Business/Marketing_and_Advertising/Internet/ Promotion/Banner_and_Link_Exchanges/).}

3. Give away an article: It has been our experience that one of the best ways to secure links to your website is to give away an article that other, related sites can include in their newsletters and/or on their websites. If this technique is appropriate, simply request that the other sites include your site's name, copyright information and a strategically worded link to your website at the beginning or end of the article. Doing this well requires good writing skills on your part as well as an understanding of the kind of content that others in your field are 


\section{Press release sites}

\section{Affiliate programs pioneered by Amazon.com}

seeking. In addition to e-mailing copies of your article to a few closely related sites, you can post your articles in a number of free content databases to which webmasters and e-zine editors refer when searching for content. A listing of a number of these sites can be found at www. google.com/Top/Arts/Writers_Resources/Self_Publishing/Free_Content/.

4. Distribute a press release: Press releases distributed through standard press release channels function in a manner similar to free articles. If effective, they are reprinted on a variety of websites, and can become the basis for articles written by journalists seeking appropriate subject matter. Perhaps, the primary advantage that links in press releases have over links in free articles is that press release sites generally have higher PageRanks than sites that might reprint free articles. This is because they tend to be news or analysis sites with lots of incoming links. Popular press release sites include PRWeb Press Release Newswire (www.prwebdirect.com), Business Wire (www. businesswire.com) and PR Newswire (www.prnewswire.com). It almost goes without saying that, if a press release is not newsworthy, online news outlets will not use it and it may not remain on press release websites for more than a few months.

5. Offer an award logo: While larger sites most likely will not respond positively to this strategy, offering an award logo (ie, the 'Silver Bullet Award of Merit') that includes a hyperlink back to your site can result in links from other websites, often from their homepage. If this strategy is used, you should insist that awardees link the logo to your site as a condition of displaying the award logo. We recommend that the awarding site provide the HTML code that awardees can paste on their webpages. That code should contain an HTML 'ALT' statement in the logo's IMG tag that includes keywords that are important to your site (ie, ALT = 'Silver Bullet Award of Merit from ABCAmmunition'). Although this strategy is not as effective as a text link, keywords in the ALT section of the IMG tag will help your ranking, since you select the awardees and, thus, the context for the link. The motivation for awardees is recognition; that is, the pride that a related site sees my site as being meritorious.

6. Establish an affiliate program: Early in the history of e-commerce, Amazon.com devised a way to get other sites to link to its site - it paid them. ${ }^{7}$ Specifically, Amazon is reputed to have created the first affiliate program through which the merchant pays an affiliated website a percentage of the sale, if someone links to the merchant's site and if that individual makes a purchase. Affiliate programs are important in and of themselves because they can bring shopper traffic to your website; however, from a linking strategy perspective, your link popularity is improved if and only if the actual link on your affiliate's site points to your site's domain. If you use affiliate management software to create and manage an affiliate program, you need to be certain that the program you choose allows each affiliate link go to your domain. Many shopping carts programs come with basic affiliate programs that should function adequately for most modest business affiliate programs. Examples of these programs include ShopSite Pro 


\section{Free services can
reward time and effort \\ Free services can
reward time and effort invested}

(http://www.shopsite.com/pro.html), StoreFront 6 (www.storefront.net) and Miva Merchant (http://smallbusiness.miva.com/products/merchant/ $\mathrm{mm} 5 /$ ). Affiliate software that installs in your server's CGI directory also is available. One example is Ultimate Affiliate (http://www. groundbreak.com/). At this point, we must state that there is some disagreement among experts regarding whether affiliate links to your site actually increase your site's PageRank. While some observers feel that Google discounts such links, Google will neither confirm nor deny that assertion. ${ }^{8}$

7. Develop a free service: A potentially effective method of obtaining links to your site is to develop a free service that is reasonably unique. For example, you might be able to include an easy-to-understand online reference manual, a mortgage calculator, a clever game or a useful database. If so, and the free service has been both professionally and strategically devised, you should obtain numerous links to your site because it includes useful information or tools for the linking sites' visitors. You should not underestimate the amount of time and effort it takes to devise, create, manage and maintain a quality resource; however, if your efforts are successful, the return can take the form of increased links, traffic, publicity and ultimately profits.

8. Establish a blog: An innovative, interesting, informative and/or controversial business blog also can be used to secure incoming links. To obtain those links (and get credit for them on Google), it is vital that the blog be hosted on your own website, rather than on that of an application service provider. Free software, such as WordPress (www.wordpress.org), can be used for this purpose.

9. Create an online forum: Online forums, or bulletin boards, allow the webmaster to establish discussion topics to which other individuals can respond with questions, answers and comments. The goal is for hundreds of forum members to build valuable content over time without your having to be involved, except of course in monitoring the site for spurious posts. Ultimately, if participants view your forum as being useful, they most likely will link to it and perhaps will recommend it on their own websites. As with most other strategies for obtaining incoming links, software is available to manage online forums. Examples include Invision Power Board (www.invisionboard. com), vBulletin (www.vbulletin.com) and phpBB (www.phpbb.com).

10. Include an abundance of valuable content: We feel that there is no substitute for an abundance of valuable content on a website. In general, the larger a site is, the more importance Google attaches to it. Although it is quite possible that Google and other leading search engines discount internal links (links to other pages within your site), if a search engine happens not to adjust for them, then 'the site with the most pages wins' (as long as your pages link to each other). Furthermore, each article with its own individual title and pattern of keywords increases the chance that your site will be shown when those words are entered into a search engine. Naturally, the more professional and useful your content is, the more others will be led to link to articles on your website. If you regularly distribute an e-mail 


\section{Include spider-friendly webpages that contain key information and links}

newsletter, a simple method of increasing content on your site is to archive those newsletters so visitors can access them.

11. Link to the websites that link to your site: While using LinkMaps (http://www.bruceclay.com/web_linkmaps.htm), to analyse incoming links to his website, one of the authors discovered that many links to his site appearing in one search engine's index did not appear in other indexes. On further investigation, this remained the case even after he accounted for the fact that Google generally reports a low number of incoming links when one uses its 'link: domain.com' syntax. Situations such as this may exist because a number of links to your site may be on linking pages deep within websites, and search engines bots simply have not spidered them. One way to help alleviate this situation is to include spider-friendly webpages on your site that contain information about, and links to, the websites that link to your site. The objective here is that, as time passes, an increasing number of the sites that link to your site will be spidered and indexed by the search engine because your specially designed webpages now point to those sites. Although this does not produce a greater number of incoming links to your site, it does help you capitalise on your existing links and increases the likelihood that all the major search engines will eventually find and index the sites that link to yours. While this task can be accomplished manually, software such as LinkMaps has the ability to automate the process.

12. Pay for text links to your website: Site owners who want to increase their link popularity rapidly can do so by investing in welltargeted links to their sites. The market in which this can be accomplished, referred to as the 'text link advertising' market, has been growing. It includes several firms, an example of which is LinkAdage (www.linkadage.com), a free service that provides three means through which links can be purchased ${ }^{9}$ :

- LinkAdage Auctions - Participants can bid on text links from over 1,000 participating sites, or can sell text links on their own website through LinkAdage auctions. Prices are determined by the top bids and appear to range from $\$ 30$ to $\$ 150$ per month, and sometimes more for some categories.

\section{Ways of purchasing links}

- LinkAdage Brokerage - Allows webmasters who do not want to use the auction mechanism to buy and sell website links through a full service text link brokerage firm, Text Link Ads, Inc. Prices are kept relatively low since LinkAdage purchases lots of text ads from important sites and then resells them individually to its clients.

- Link Adage Link Exchange - Provides both automated and manual mechanisms for trading links.

\section{Summary}

In this two-part series, we have introduced the reader to the fundamentals of how search engines operate and have discussed a number of suggestions for steps e-marketers can take to improve their 
sites' search engine rankings. Since those rankings basically are determined by two overall factors, keywords and links from other sites, our first paper dealts with strategies for optimising a site's keywords in preparation for search engine spiders, while the present paper dealt with strategies for obtaining linkages from other sites. Although our primary focus was on a site's ranking in Google searches, the information we have provided should prove useful for increasing a site's ranking on other search engines as well.

Although search engines will evolve through time, thus requiring new advice and recommendations, we feel that the information and advice we have provided in this two-paper series should be of considerable use to those wanting to better understand the SEO process and to take steps to optimise their own search engine rankings.

\section{References and Notes}

1. Burns, E. (2005) 'How do the search engines stock up?' document on the Internet (http:// www.clickz.com/stats/sectors/search_tools/article.php/3528456), August 18.

2. Google (2006) 'Technology overview', document on the Internet (http://www.google.com/ corporate/tech.html), January 24.

3. Grehan, M. (2004). Search engine marketing, ebook on the Internet (http://www.search-enginebook.co.uk/).

4. Wu, B. and Davison, B. D. (2005) 'Identifying link farm spam pages', Proceedings of the 14th International World Wide Web Conference, Industrial Track, document on the Internet (http://citeseer.ist.psu.edu/wu05identifying.html).

5. Craven, P. (2006) 'Google's PageRank explained', document on the Internet (http://www. webworkshop.net/pagerank.html), May 19.

6. Rohde, L. (2006). OptiLink, Windrose Software, Portland, OR, (http://www.windrosesoftware. com/optilink/).

7. Schwartz, E. I. (1999). Digital Darwinism, Broadway Books, New York, p. 71.

8. Wilson, R. (2006) Dr. Wilson's Plain-Spoken Guide to Search Engine Optimization, (2006 edn), Wilson Internet Services, Rocklin, CA.

9. LinkAdage (2006) 'Buy links, sell links, and exchange links', document on the Internet (www.linkadage.com). 